\title{
Fetal/Neonatal Pericardial Effusion in Down's Syndrome: Case Report and Review of Literature
}

\author{
Pramod Pharande, DCH, FRACP, CCPU 1,2,3 Kiran Kumar Balegar Virupakshappa, FRACP ${ }^{1,2}$ \\ Bhavesh Mehta, FRACP ${ }^{4,5}$ Nadia Badawi, FRACP, PhD ${ }^{4,5}$
}

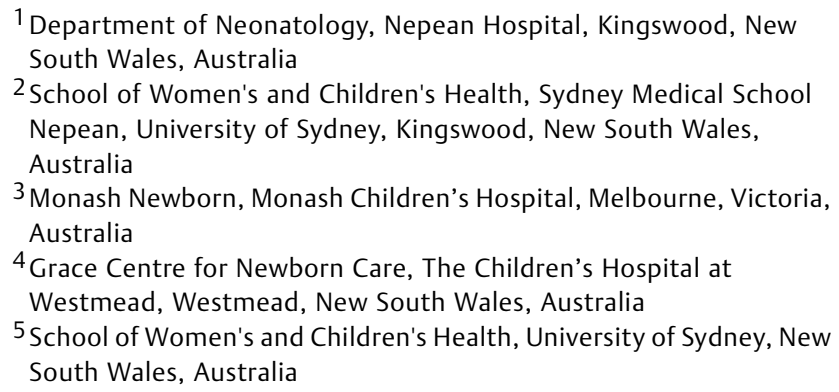

Address for correspondence Kiran Kumar Balegar Virupakshappa, FRACP, Department of Neonatology, Nepean Hospital, Derby Street, Kingswood, New South Wales 2747, Australia

(e-mail: Kiran.Balegarvirupakshappa@health.nsw.gov.au).

Am J Perinatol Rep 2018;8:e301-e306.

\begin{abstract}
Keywords

- Down's syndrome

- hypothyroidism

- pericardial effusion

- steroid

- transient myeloproliferative disorder

We report a preterm (35 ${ }^{4 / 7}$ weeks) male neonate with Down's syndrome (DS) diagnosed with isolated pericardial effusion (PE) at 20 weeks of gestation. He was born by precipitous delivery, needed no resuscitation and presented within first 24 hours of life with respiratory distress, anemia due to feto-maternal bleed, hypotension, hepatomegaly, and coagulopathy. Postnatal echocardiography confirmed a $5 \mathrm{~mm}$ rim of PE without tamponade, normal cardiac structure, and function. He was stabilized with ventilation, packed red cell, fresh frozen plasma, inotropes (dopamine, dobutamine, and adrenaline), and steroid (hydrocortisone). Subsequent evaluation confirmed hypothyroidism, transient myeloproliferative disorder (TMD), hepatic failure due to fibrosis/cirrhosis with portal hypertension, and steroid sensitive hypotension on two occasions possibly due to adrenal insufficiency. PE completely resolved over 2 weeks. In view of progressively worsening liver failure with ascites and portal hypertension, the family opted for palliation. Literature review has been discussed regarding perinatal onset of PE in DS.
\end{abstract}

Pericardial effusion (PE) is occasionally reported in children with Down's syndrome (DS) either in isolation ${ }^{1}$ (isolated PE) or as part of hydrops. ${ }^{2}$ It can be associated with congenital hypothyroidism ${ }^{3}$ and transient myeloproliferative disorder (TMD). ${ }^{4}$ The pathogenesis of PE in DS is unclear. We describe a case of antenatally detected isolated pericardial effusion in DS in association with TMD, liver failure, hypothyroidism, and hypotension due to possible adrenal insufficiency. We reviewed the literature to understand the underlying mechanism, demography, association, and natural course of PE.

received

July 26, 2018

accepted

September 5, 2018
DOI https://doi.org/

10.1055/s-0038-1675337. ISSN 2157-6998.

\section{Case Report}

Antenatal morphology scan and fetal echocardiography in a 39year-old G3P3 mother revealed isolated PE with structurally normal heart, first identified at 20 weeks of gestation. Subsequent amniocentesis confirmed DS $(47, \mathrm{XY})$. A male neonate at $35^{4 / 7}$ weeks gestation, birth weight $1,880 \mathrm{~g}\left(<10^{\text {th }}\right.$ centile $)$ was vaginally born at home through precipitous labor, needed no resuscitation and was retrieved to a tertiary Neonatal Intensive Care Unit by ambulance at 40 minutes of age. Initial examination showed moderate respiratory distress with $\mathrm{FiO}_{2}$ (fraction

Copyright $\odot 2018$ by Thieme Medical Publishers, Inc., 333 Seventh Avenue, New York, NY 10001, USA.

License terms Tel: +1(212) 584-4662.

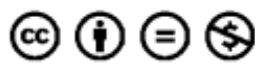


of inspired oxygen) 0.3 , pallor ( $\mathrm{Hb} 83 \mathrm{~g} / \mathrm{L}$ ), normal cardiovascular examination with normal noninvasive blood pressure $(60 /$ 32, mean: 45), massive hepatomegaly ( $6 \mathrm{~cm}$ below costal margin) in the background of phenotypic DS. There was no hydrops, ascites or splenomegaly. He was stabilized with mechanical ventilation and packed cell transfusion $(10 \mathrm{~mL} / \mathrm{kg}$ twice). His liver function and coagulation profile were deranged: alanine transaminase (ALT) $318 \mathrm{IU} / \mathrm{L}$, aspartate transaminase (AST) 1,147 IU/L; total bilirubin $41 \mathrm{micromol} / \mathrm{L}$, direct bilirubin 6 micromol/L; alkaline phosphatase $163 \mathrm{IU} / \mathrm{L}$; gamma glutamyl transferase (GGT) $389 \mathrm{IU} / \mathrm{L}$; prothrombin time 46 second; activated partial thromboplastin time (APTT) 128 second international normalized ratio (INR) 5.2; fibrinogen 1.2 $\mathrm{g} / \mathrm{L}$; ammonia $69 \mathrm{micromol} / \mathrm{L}$. There was no spontaneous bleeding. He received fresh frozen plasma $(10 \mathrm{~mL} / \mathrm{kg})$. Echocardiography showed normal structure apart from a generous interatrial communication with predominant left to right shunt. There was a global pericardial effusion measuring $5 \mathrm{~mm}$ in four chamber view in diastole, with a larger pocket located anteromedially (-Fig. 1). There was a good biventricular function and no evidence of tamponade.

Over the next 6 hours, he developed progressively worsening hypotension (lowest invasive BP [blood pressure] of 31/18, mean: 23) refractory to volume boluses and multiple inotropes (Dopamine 20 microgram $/ \mathrm{kg} / \mathrm{min}$; Dobutamine 20 microgram $/ \mathrm{kg} / \mathrm{min}$; adrenaline $0.5 \mathrm{microgram} / \mathrm{kg} / \mathrm{min}$ ) in escalating doses. Blood pressure started to improve after commencing hydrocortisone ( $2 \mathrm{mg} / \mathrm{kg} /$ loading dose, once followed by $1 \mathrm{mg} /$ $\mathrm{kg} /$ dose 6 hourly). Cortisol level was not obtained prior to commencing. In view of multitude of problems he was transferred to the Children's Hospital for further management.

Echocardiography on admission to the Children's Hospital confirmed the same findings.

Inotropes were weaned slowly and stopped after 48 hours. He was extubated to continuous positive airway pressure (CPAP) on day 3 and hydrocortisone was stopped the next day. He remained normotensive without hydrocortisone until day 19. Pericardial effusion was also completely resolved over next 2 weeks. Haematological findings were investigated. Kleihauer's test result indicated $37 \mathrm{~mL}$ fetal blood loss that accounted for the initial anemia ( $\mathrm{Hb} 83 \mathrm{~g} / \mathrm{L}$ ). However, white cell count was elevated $\left(30.1 \times 10^{9} / \mathrm{L}\right)$ and blood film showed blast cells $\left(2.1 \times 10^{9} / \mathrm{L}\right)$. Although the initial platelet count was normal $\left(190 \times 10^{9} / \mathrm{L}\right)$ there was a subsequent drop in the count over next few days (lowest $26 \times 10^{9} / \mathrm{L}$ ). This prompted a bone marrow examination that showed $15 \%$ blast cells confirming the diagnosis of TMD. The thyroid function test revealed a raised TSH (thyroid stimulating hormone; 28.05 $\mathrm{mU} / \mathrm{L}$ ) and low normal T4 (14.6 pmol/L) confirming subclinical hypothyroidism. He was commenced on L-thyroxine treatment that normalized thyroid function.

On day 19, he developed an acute deterioration with severe hypotension (lowest BP 39/12 with the mean of $21 \mathrm{~mm} \mathrm{Hg}$ ), was mechanically ventilated and commenced on volume bolus followed by inotropes (Adrenaline 0.2 microgram $/ \mathrm{kg} / \mathrm{min}$ and Dobutamine $10 \mathrm{microgram} / \mathrm{kg} / \mathrm{min}$ ) to which he did not respond. He was then restarted on hydrocortisone at $1 \mathrm{mg} /$ $\mathrm{kg} /$ dose 6 hourly with good response. Unfortunately, no cortisol level was obtained prior to commencing on hydrocortisone. He was continued on maintenance dose of hydrocortisone with a view to wean it at a later stage and perform an ACTH (adrenocorticotropic hormone) stimulation test (synacthen test); however, this was not achieved prior to his death.

He developed progressive liver failure, splenomegaly with ascites. Investigations showed elevated transaminases and deranged coagulation profile. TORCH screening (Toxoplasma, Others, Rubella Cytomegalovirus, Herpes Simplex Virus), metabolic work-up including $\alpha 1$ antitrypsin, urine metabolic screen, and transferrin isoform were negative. Tense ascites needed peritoneal drainage of large amount of transudate. Ultrasound showed coarse echogenicity consistent with liver fibrosis/ cirrhosis and collaterals suggestive of portal hypertension.

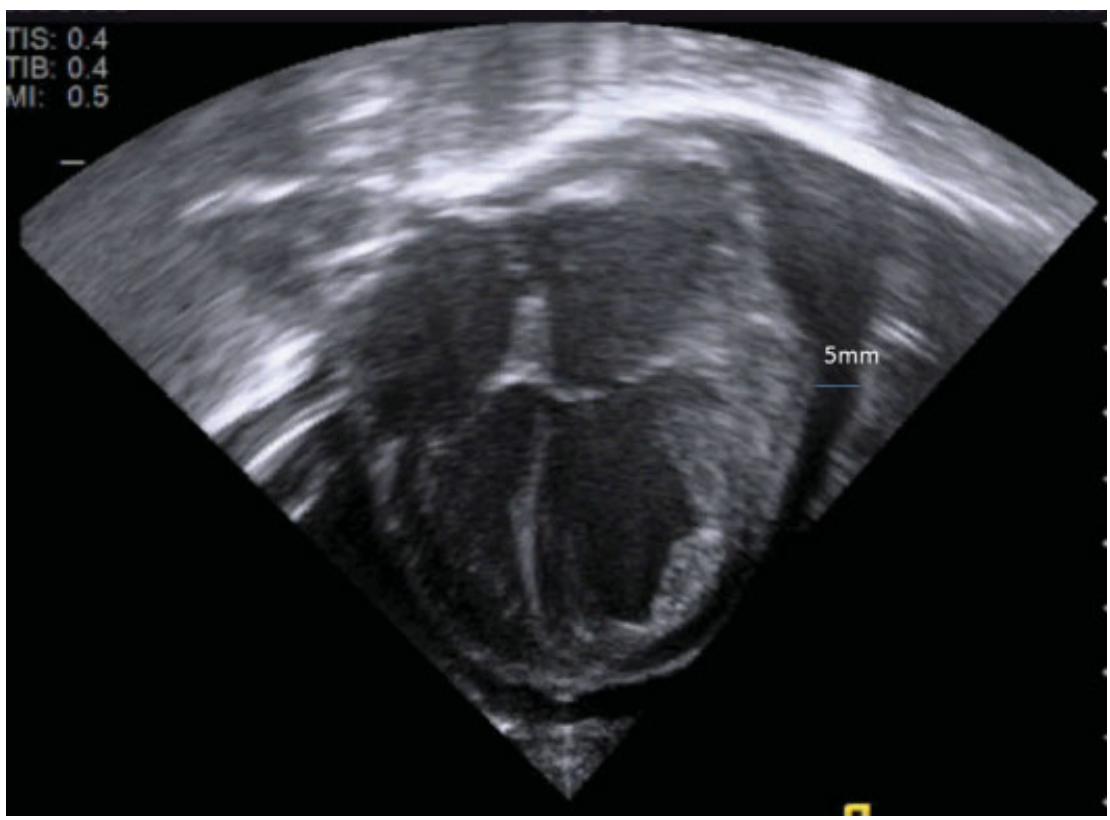

Fig. 1 Echocardiographic image showing pericardial effusion. 
Multidisciplinary team opined that in view of continued deterioration despite maximal supportive therapy in the background of multiple issues, redirection of care was thought to be in his best interest. The family accepted the offer of palliative care course. He died on day 39, soon after extubation in the presence of his family. The post mortem autopsy was not performed as per the parental request.

\section{Discussion}

Our case with DS exhibited isolated PE without hydrops, TMD, hypothyroidism, liver failure with portal hypertension and possible adrenal insufficiency. The literature review (summarized in - Table 1) was undertaken to establish the etiopathogenesis, presentation, associated findings, natural course, and management of fetal and neonatal pericardial effusion.

\section{Pathogenesis of PE in DS}

Mechanisms producing isolated PE in fetus/neonate are not completely understood. TMD develops in 3 to $10 \%$ of newborns with DS, ${ }^{5}$ is characterized by clonal proliferation of blast cells in blood/bone marrow and may be responsible for pericardial effusion. ${ }^{1,2,4,6-13}$ Pericardial effusion in TMD may occur due to myocardial infiltration by degranulating eosinophils ${ }^{13}$ or epicardial infiltration by atypical myeloid cells. ${ }^{10}$ It is also presumed that effusion could be related to an abnormal production of cytokines at the effusion site. ${ }^{6}$ PE has been demonstrated to be in association with hypothyroidism and celiac disease in early childhood ${ }^{3,14-16}$ but not in the perinatal period. Our case had both TMD and hypothyroidism.

\section{Age of Onset}

Most of the reported cases have been diagnosed either in the second or third trimester as PE is easily detected with ultrasound. PE has been diagnosed as early as $\left(11^{6 / 7}-16^{4 / 7}\right)$ weeks. $^{2}$ Sharland and Lockhart ${ }^{17}$ reported 35 cases of PE detected at 18 to 25 weeks gestational age (GA) out of which 9 were confirmed to have DS arguing the importance of fetal karyotyping in cases of PE. Our case was diagnosed at 20weeks GA and was monitored in utero. The others ${ }^{1,6,8-10,12,13}$ have diagnosed them at 30 to36 weeks GA. Two cases were diagnosed in neonatal period ( 2 weeks) as one of them had no antenatal care $^{4}$ and the authors have not reported about antenatal screening in other case. ${ }^{7}$ Al-Kasim et al $^{11}$ have reported six cases of PE, all diagnosed within 2 weeks of birth at full term gestation except one who was diagnosed at 35 weeks.

\section{Cardiac Manifestation}

In most reported cases the heart was structurally normal but some have reported associated ASD (atrial septal defect), ${ }^{4,11}$ VSD (ventricular septal defect), ${ }^{1,11}$ dextrocardia, ${ }^{17}$ and PDA (patent ductus arteriosus). ${ }^{11} \mathrm{PE}$ has been reported to be either isolated or associated with hydrops, ${ }^{2,8,10,11}$ manifesting either without cardiovascular compromise ${ }^{1,4,6,13,17}$ or with cardiac tamponade $\mathrm{e}^{7,9-11}$ needing intervention. Isolated PE has been reported to progress to worsening hydrops ${ }^{2,8,10,11}$ and intra uterine death ${ }^{2}$ or complete resolution. ${ }^{11}$ Our case presented with isolated PE with no structural cardiac anomalies or cardiac tamponade and resolved spontaneously.

\section{Associated Malformation}

Hepatomegaly, 2,4,6-8,10,11,13 splenomegaly, ${ }^{2,8,10,11,13}$ skin nodules, ${ }^{11}$ and petechiae ${ }^{12}$ raises the possibility of TMD and has been consistently found in most of the cases of PE. 1,2,4,6-8,10-13 Occasionally, PE can be associated with acute myeloid leukemia ${ }^{9}$ and congenital hypothyroidism. ${ }^{1}$ Our patient had TMD and hypothyroidism. An interesting finding in our case was the temporal association between the administration of hydrocortisone and resolution of circulatory collapse on more than one occasion creating a convincing argument for possible adrenal insufficiency. Such an association has not been previously reported to the best of our knowledge.

\section{Treatment}

In utero

Pericardiocentesis in utero ${ }^{8-10}$ has been occasionally attempted successfully so as to prolong the pregnancy but others have chosen expectant management ${ }^{1,6,12,17}$ when PE was not associated with cardiovascular compromise.

\section{Postnatal}

Isolated PE can be managed expectantly until its spontaneous resolution. Sharland and Lockhart ${ }^{17}$ have reported complete resolution of PE without treatment in one preterm (28 weeks) and two term neonates. Pericardiocentesis is usually undertaken when PE leads to either cardiac tamponade ${ }^{7}$ or contributes to significant respiratory compromise. ${ }^{4,6,13}$ A short course of steroid (prednisolone) therapy for 2 weeks ${ }^{1,4,7}$ has been used to facilitate resolution of PE. Occasionally a prolonged course of steroid over $6^{6}$ to 12 weeks ${ }^{13}$ was required to achieve resolution of PE. Most of the cases of PE are associated with TMD. TMD has favorable outcome with complete remission within the first 3 months in most cases; however, in infants with severe and life-threatening symptoms (high white cell count, bleeding diatheses, liver fibrosis, and effusion) treatment with low dose cytarabine $(1 \mathrm{mg} / \mathrm{kg} /$ day $\times 7$ days $)$ has a beneficial effect. ${ }^{18}$ In two term neonates with haemodynamically significant PE associated with TMD, a short course of cytarabine resulted in remarkable improvement and resolution of PE. ${ }^{11}$ Oh et al ${ }^{12}$ have used low-dose cytarabine in their patient with a large PE associated with TMD to prevent the development of hepatic fibrosis and achieved complete resolution of PE and TMD. In one of the case reports ${ }^{1}$ thyroxine was used for hypothyroidism but it was started when PE had already resolved with steroid therapy. In our case, the short course of hydrocortisone for first 3 days given for the management of hypotension may have expedited resolution of PE. It had already resolved by the time thyroxine was commenced, thereby negating its role in facilitating PE resolution in our case.

\section{Outcome}

The outcome of neonates with PE in DS is difficult to ascertain as sometimes the parents opt for termination of pregnancy. ${ }^{10,17}$ The prognosis is worse if PE is associated 


\begin{tabular}{|c|c|c|c|c|c|c|c|c|c|}
\hline & 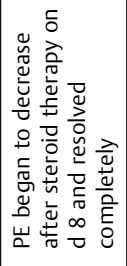 & 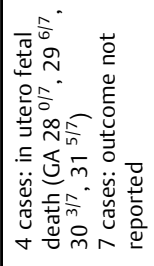 & 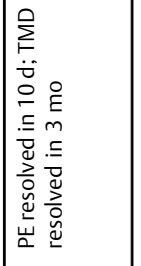 & 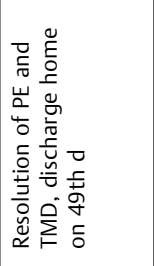 & 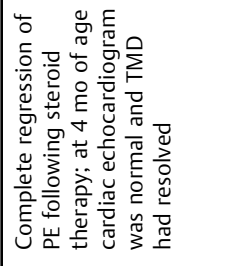 & 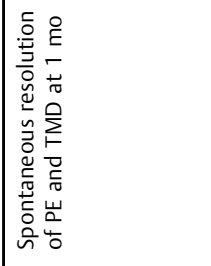 & 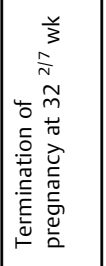 & 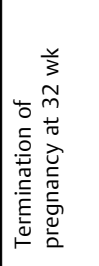 & 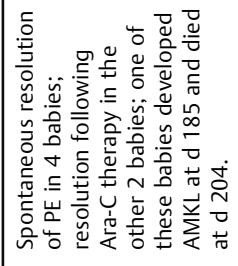 \\
\hline & 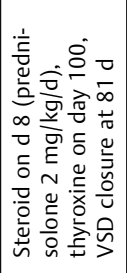 & 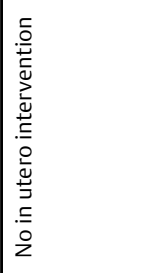 & 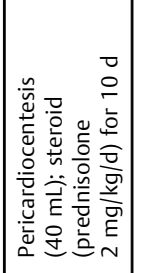 & 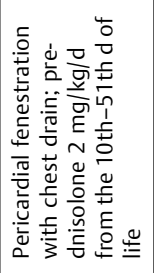 & 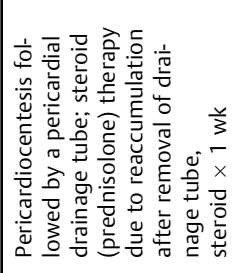 & 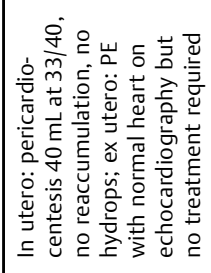 & 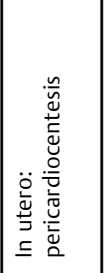 & 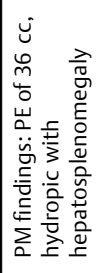 & 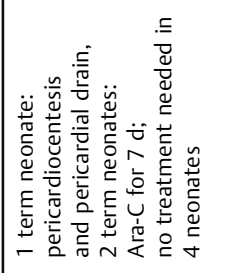 \\
\hline 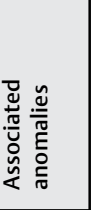 & 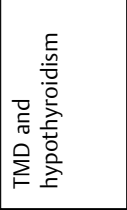 & 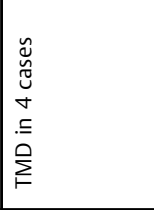 & 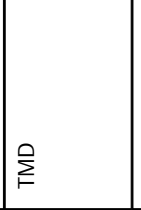 & 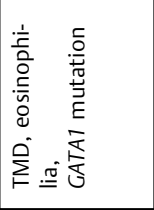 & $\sum_{i}$ & 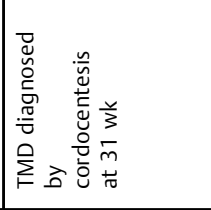 & $\vec{\xi}$ & 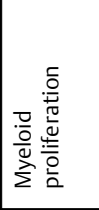 & 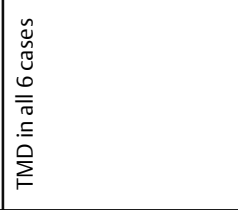 \\
\hline 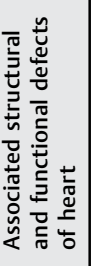 & 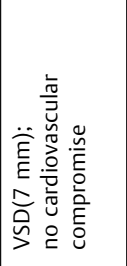 & 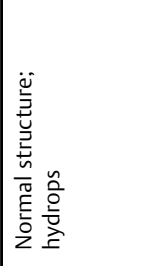 & 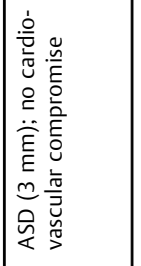 & 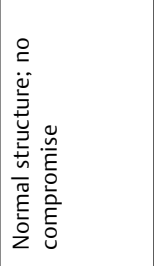 & 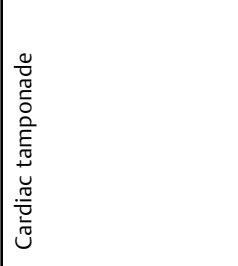 & 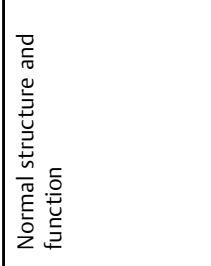 & 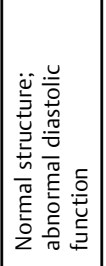 & 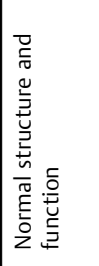 & 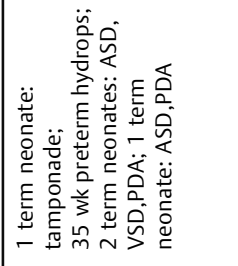 \\
\hline & 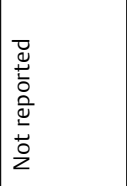 & 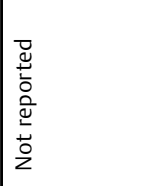 & 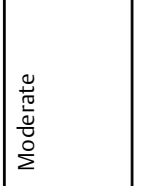 & 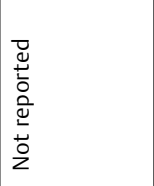 & 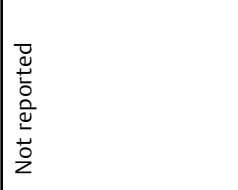 & 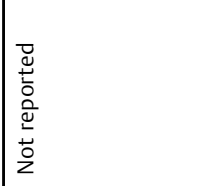 & $\mid \begin{array}{l}E \\
\stackrel{E}{E} \\
\simeq\end{array}$ & $\mid \begin{array}{l}E \\
E \\
\end{array}$ & 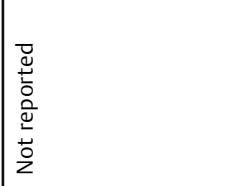 \\
\hline 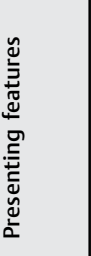 & $\begin{array}{l}\underline{a} \\
0 \\
0 \\
\underline{0} \\
\frac{\pi}{0} \\
\underline{0}\end{array}$ & 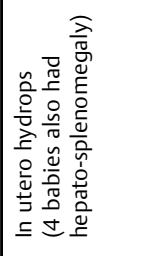 & 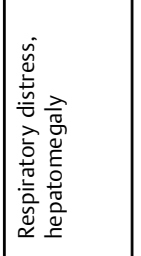 & 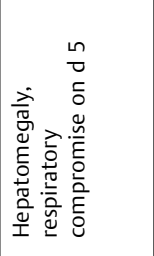 & 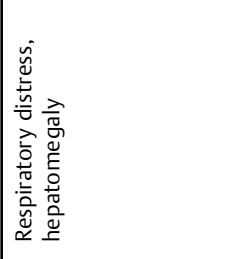 & 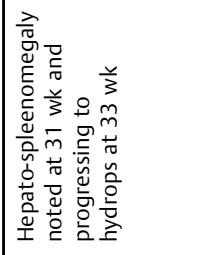 & 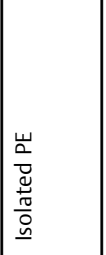 & 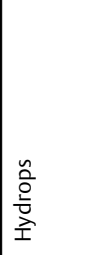 & 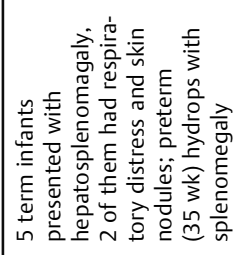 \\
\hline 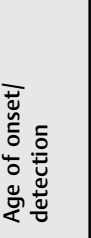 & 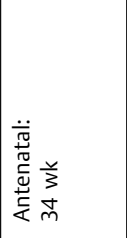 & 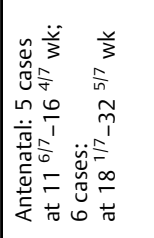 & 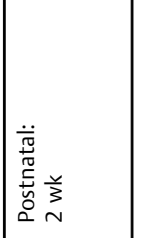 & 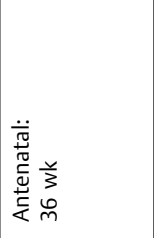 & 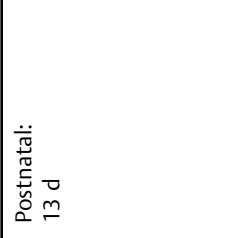 & 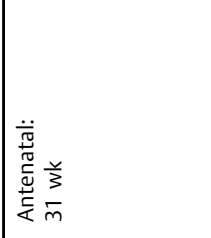 & 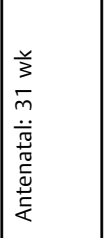 & 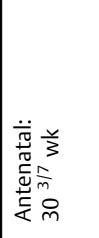 & 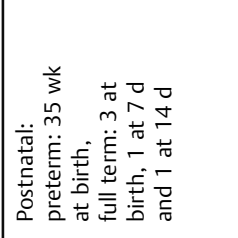 \\
\hline 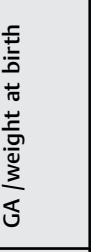 & 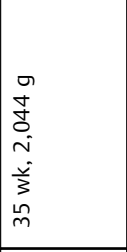 & 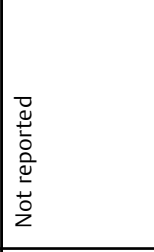 & 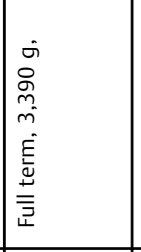 & 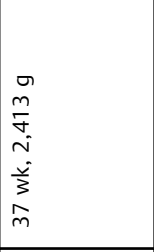 & 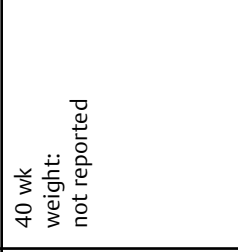 & 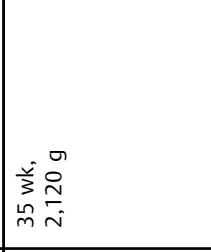 & 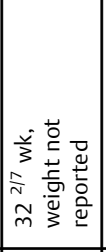 & 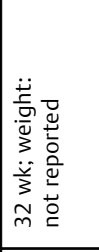 & 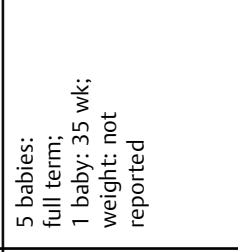 \\
\hline 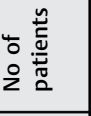 & - & $=$ & - & - & - & - & - & - & 0 \\
\hline تٍٍِّّ & 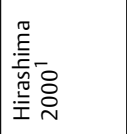 & 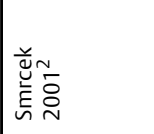 & 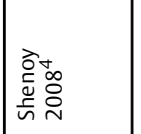 & 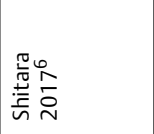 & 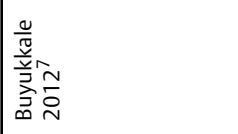 & 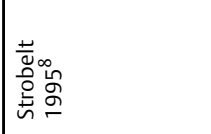 & 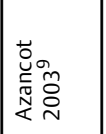 & 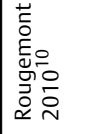 & 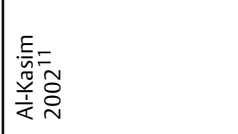 \\
\hline
\end{tabular}




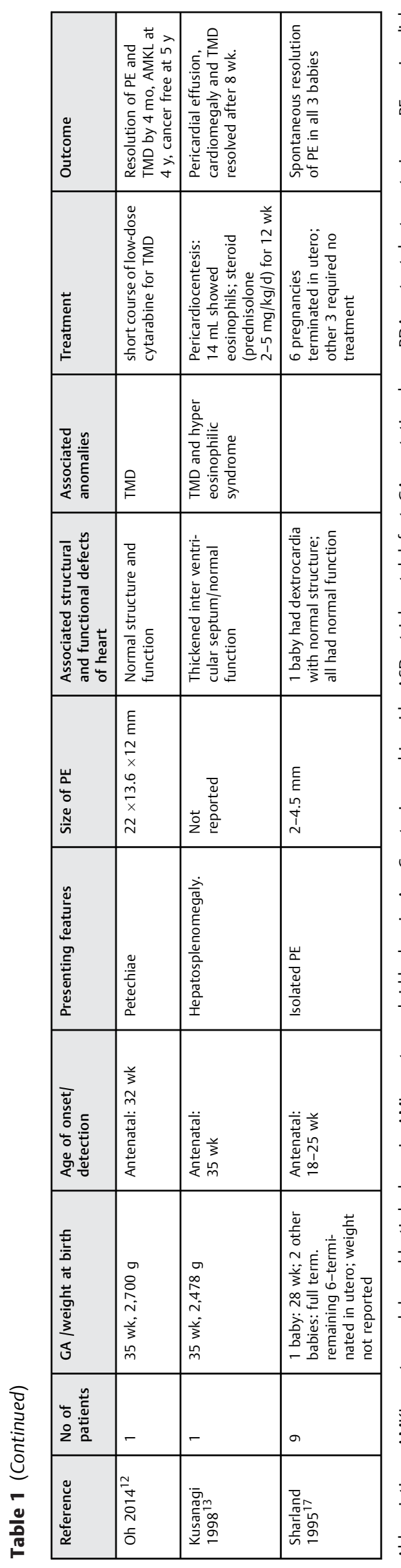

with hydrops fetalis as the risk of intrauterine death is very high as reported by Smrcek et $\mathrm{al}^{2}$ in 4/11 cases with hydrops. Occasionally, a spontaneous resolution ${ }^{11}$ or reversal of hydrops by in utero pericardiocentesis and complete resolution of PE has been achieved. ${ }^{8}$ PE associated with $\mathrm{TMD}^{1,4,6-8,11-13}$ had complete resolution of PE either spontaneously or with treatment. Our index case had liver fibrosis associated with TMD. The outcome is fatal when liver fibrosis develops with TMD. The literature review shows that $94 \%$ of DS cases with TMD complicated by liver fibrosis had died by the age of 150 days. $^{19}$ Our case had similar outcome, although we had chosen the palliation pathway in agreement with family due to liver failure.

\section{Conclusion}

Our case report along with a comprehensive review of other case reports of perinatal onset of PE in DS indicate that PE can be isolated or part of hydrops, asymptomatic or present with tamponade, can have associated cardiac and noncardiac anomalies, the most common being TMD. PE in association with TMD and liver failure has been reported to have a poor prognosis as in our case. PE usually resolves spontaneously but sometimes need medications (prednisolone/cytarabine). PE associated with adrenal insufficiency in DS has not been previously described. While not proven, we assume this baby had adrenal insufficiency based on the temporal association between resolution of hypotension and commencement of hydrocortisone at two different time points during the course.

\section{Ethical Approval}

The article is a case report and does not contain any studies with human or animal participants performed by any of the authors. The scientific report does not reveal patient identity anywhere.

\section{Conflict of Interest}

The authors declare that they have no conflict of interest.

\section{References}

1 Hirashima C, Eguchi Y, Kohmura Y, Minakami H, Sato I. Isolated pericardial effusion and transient abnormal myelopoiesis in a fetus with Down's syndrome. J Obstet Gynaecol Res 2000;26(04):303-306

2 Smrcek JM, Baschat AA, Germer U, Gloeckner-Hofmann K, Gembruch U. Fetal hydrops and hepatosplenomegaly in the second half of pregnancy: a sign of myeloproliferative disorder in fetuses with trisomy 21. Ultrasound Obstet Gynecol 2001;17(05):403-409

3 Dinleyici EC, Ucar B, Kilic Z, Dogruel N, Yarar C. Pericardial effusion due to hypothyroidism in Down syndrome: report of four cases. Neuroendocrinol Lett 2007;28(02):141-144

4 Shenoy RD, Bhat KG, Kamath N, Kumble Y. Transient myeloproliferative disorder and eosinophilic pericardial effusion in a down syndrome neonate. Pediatr Hematol Oncol 2008;25(02):123-129

5 Zwaan CM, Reinhardt D, Hitzler J, Vyas P. Acute leukemias in children with Down syndrome. Hematol Oncol Clin North Am 2010;24(01):19-34

6 Shitara Y, Takahashi N, Aoki Y, et al. Cytokine profiles in pericardial effusion in a Down syndrome infant with transient abnormal myelopoiesis. Tohoku J Exp Med 2017;241(02):149-153 
7 Buyukkale G, Cetinkaya M, Akcay A, et al. Transient leukemiaassociated pericardial tamponade in a neonate with Down syndrome. Pediatr Hematol Oncol 2012;29(04):386-388

8 Strobelt N, Ghidini A, Locatelli A, Vergani P, Mariani S, Biondi A. Intrauterine diagnosis and management of transient myeloproliferative disorder. Am J Perinatol 1995;12(02):132-134

9 Azancot A, Diehl R, Dorgeret S, et al. Isolated pericardial effusion in the human fetus: a report of three cases. Prenat Diagn 2003;23 (03):193-197

10 Rougemont AL, Makrythanasis P, Finci V, et al. Myeloid proliferation without GATA1 mutations in a fetus with Down syndrome presenting in utero as a pericardial effusion. Pediatr Dev Pathol 2010;13(05):423-426

11 Al-Kasim F, Doyle JJ, Massey GV, Weinstein HJ, Zipursky A; Pediatric Oncology Group. Incidence and treatment of potentially lethal diseases in transient leukemia of Down syndrome: Pediatric Oncology Group Study. J Pediatr Hematol Oncol 2002; 24(01):9-13

12 Oh LZ, Ng PM, Quah TC. A dysmorphic newborn with petechiae and a 'Big Heart'. BMJ Case Rep 2014;2014:bcr2014204195
13 Kusanagi Y, Ochi H, Matsubara K, Ito M. Hypereosinophilic syndrome in a trisomy 21 fetus. Obstet Gynecol 1998;92(4, Pt 2):701-702

14 Concolino D, Pascuzzi A, Pietragalla E, Lia R, Canepa S, Strisciuglio P. High prevalence of isolated pericardial effusion in Down syndrome. Am J Med Genet A 2005;132A(03):331-332

15 Bhardwaj P, Sharma VK, Bhardwaj R. Hypothyroidism presenting as cardiac tamponade in Down syndrome. J Indian Med Assoc 2011;109(01):47-48

16 Werder EA, Torresani T, Navratil F, et al. Pericardial effusion as a sign of acquired hypothyroidism in children with Down syndrome. Eur J Pediatr 1993;152(05):397-398

17 Sharland G, Lockhart S. Isolated pericardial effusion: an indication for fetal karyotyping? Ultrasound Obstet Gynecol 1995;6(01):29-32

18 Bruwier A, Chantrain CF. Hematological disorders and leukemia in children with Down syndrome. Eur J Pediatr 2012;171(09): 1301-1307

19 Shiozawa Y, Fujita H, Fujimura J, et al. A fetal case of transient abnormal myelopoiesis with severe liver failure in Down syndrome: prognostic value of serum markers. Pediatr Hematol Oncol 2004;21(03):273-278 